\title{
A Bizarre Presentation of Bilateral Mandibular Osteoporotic Bone Marrow Defect (A Case Report)
}

\author{
Abbas Al-Ramzi, Maysoun Kasem, and Karim M. Adel
}

\section{ABSTRACT}

BACKGROUND: Osteoporotic bone marrow defect of the jaw is an uncommon localized radiolucency that consists of hematopoietic red marrow with varying amounts of fatty yellow marrow. The lesion is usually asymptomatic and accidentally discovered during a routine radiographic examination; however, some studies showed different results.

CASE REPORT: This is an uncommon case of bilateral mandibular osteoporotic bone marrow defect in a 40 -year- old healthy female. One of the defects reoccurred, and it involves dental implants.

PLAN OF TREATMENT: Lesion was managed by curettage and the patient was followed up after 1,6,12 months.

CONCLUSIONS: in order to diagnose FOBMD and differentiate it from other lesions, further researches are needed to help fully understand it, since the exact incident and etiology are not established yet.

Keywords: bone marrow defect, hematopoietic origin, jaw radiolucency, mandible.

\author{
Published Online: April 09,2020 \\ ISSN: $2684-4443$ \\ DOI : 10.24018/ejdent.2020.1.2.4 \\ Abbas Al-Ramzi \\ Unit of Oral and Maxillofacial \\ Surgery, Bnied-Al-Gar Dental Centre \\ and Mubarak-Al-Kabeer Hospital, \\ Ministry Of Health, Kuwait. \\ (omfsbneid@gmail.com)
}

$$
\begin{aligned}
& \text { Maysoun Kasem } \\
& \text { Unit of Oral And Maxillofacial } \\
& \text { Surgery, Bnied-Al-Gar Dental Centre } \\
& \text { and Mubarak-Al-Kabeer Hospital, } \\
& \text { Ministry of Health, Kuwait. } \\
& \text { (mkassem1985@gmail.com) } \\
& \text { Karim M. Adel * } \\
& \text { - Unit of Oral and maxillofacial } \\
& \text { surgery, Bnied-Al-gar Dental Centre } \\
& \text { and Mubarak-Al-Kabeer Hospital, } \\
& \text { Ministry of health, Kuwait. } \\
& \text { - Former Assistant Lecturer, Oral and } \\
& \text { Maxillofacial Surgery, Faculty of } \\
& \text { dentistry, Future University in Egypt } \\
& \text { (krystaldental@gmail.com) } \\
& \text { *Corresponding Author }
\end{aligned}
$$

\section{INTRODUCTION}

Focal osteoporotic bone marrow defect (FOBMD) of the jaw is a localized radiolucency that is usually affect the posterior part of the mandible ${ }^{1}$ and consists of hematopoietic red marrow with varying amounts of fatty yellow marrow ${ }^{2-4}$. The lesion is usually asymptomatic and accidently discovered during a routine radiographic examination ${ }^{5}$.

Focal osteoporotic bone marrow defects commonly seen in the posterior mandible of middle-aged women. Radiographically, this lesion appears as a localized radiolucency, which differs in shape, size, trabeculae, and the definition of its borders from one patient to another6.

In order to distinguish FOBMD from other common radiolucent lesions affecting the jaws such as cysts, pseudocysts, tumors, or malignancies, a thorough clinical examination combined with radiographic evaluation and histopathological analysis should be conducted to reach the diagnosis8.

In this report, we discuss an unusual case of bilateral osteoporotic bone marrow defects of the mandible with its clinical, radiological, and histopathological findings.

\section{CASE REPORT}

A 40-year-old female, with no significant past medical history, was referred to the oral and maxillofacial surgery department in Bnied Al-Gar specialized dental center, Kuwait, from a private clinic for consultation after an accidental finding of radiolucent lesions on the both sides posterior part of the mandible the during an implant follow up visit. As detailed history was obtained from the patient recalls having surgical extractions and implant placements in areas that correspond to the lesions

\section{A. Intraoral examination}

The result of clinical examination showed healthy mucosa with no signs of abnormalities nor infection.Final Stage

When you submit your final version, after your paper has been accepted, prepare it in two-column format, including figures and tables.

\section{B. Radiographic evaluation}

A panoramic radiograph (OPG) and periapical x-rays for 
the right and left mandibular molar areas were performed for the patient. Right and left side of the mandible showed a well-defined radiolucent area with internally amorphous bone in their superior border, the lesions showed a variable cortication. Figure 1 showed the positioned of radiolucency on the right side occupying the space between two implants replacing the 1st premolar and 1st molar. Superiorly, this lesion extends to an area bellow the crest of the alveolar ridge, and inferiorly to bellow the apical regions of the implants. On the left side, the radiolucency extended between the 2nd molar and the anterior border and the ramus, superiorly it extended to the crest of the alveolar ridge and to the inferior alveolar canal inferiorly without violating it. The two lesions were asymptomatic and had no effect on the mandibular cortex.

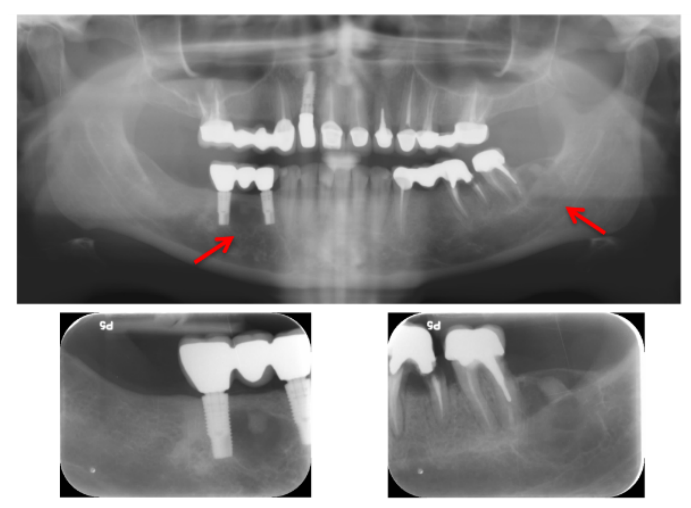

Fig 1. Panoramic radiograph, right and left periapical Xray showing the bilateral FOBMD in the posterior molar region of the mandible (arrows)

\section{Laboratory investigation}

Under local anesthesia, a biopsy was taken from the left edentulous side and the two bony tissues bits inside the lesion were sent to pathological evaluation. The histopathological analysis described the biopsy to have both connective tissue and the calcified structure composition contents (figure 2). The connective tissue showed dense cellularity that resemble the normal hematopoietic bone marrow characters; erythroid, monocytic, and granulocytic series, as well as fat cells, megakaryocytes, and sparse collagen fibers. The two calcified structures were composed of irregular trabeculae of osteoid and lobulated basophilic masses of cementum. It didn't show any signs of abnormal cell morphology or malignancy.

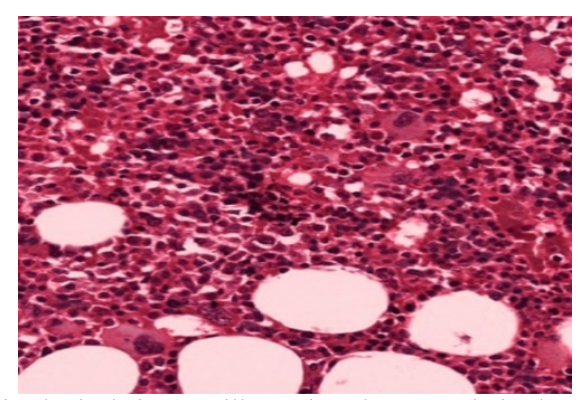

Fig 2. Histological image illustrating hematopoietic bone marrow composed of erythroid, granulocytic, monocytic, lymphocytic series and megakaryocytes associated with fatty marrow

\section{Final diagnosis}

Based on the patient age, sex, lesions locations, clinical and radiographic finding, and histopathological examination, the lesion was diagnosed as focal osteoporotic bone marrow defect of the mandible

\section{E. Treatment}

The lesions were managed by curettage.

\section{F. Follow up}

After one-year, Radiographs were taken (Figure 3) and it showed signs of osseous repair, more on the left side than the right one. The right lesion was being monitored for any future complication such as implants displacement

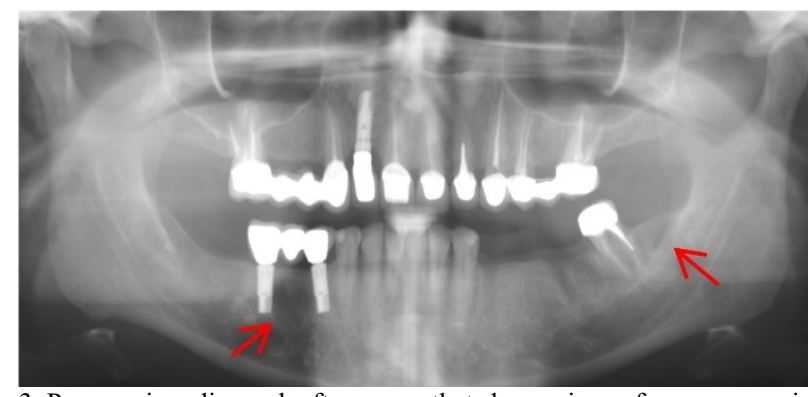

Fig 3. Panoramic radiograph after a year that shows signs of osseous repair in the lesion on left side more than the right side

\section{DISCUSSION}

Hematopoietic red bone marrow is found in all newborns' marrow. However, in adult jaws, the yellow bone marrow comprises around $75 \%$, while the red bone marrow is about $25 \%{ }^{5}$ and is usually restricted to the angle of the mandible, maxillary tuberosity, and condylar process in the jaws. FOBMD is usually found in the posterior mandible of females in their fourth to fifth decades of life ${ }^{7}$. The incident of FOBMD is not established yet, since most of the cases are clinically asymptomatic and discovered accidently ${ }^{8}$.

Radiographically, FOBMD varies in its presentation from sharply defined radiolucency with precise border to illdefined radiolucency with irregular borders. This lesion also varies in size from a few millimeters to several centimeters in diameters and the presence and type of trabiculations ${ }^{5}$. Some FOBMDs are multifocal, bilateral ${ }^{9}$.

This report presents a case with same common demographic, clinical, radiographical, and histopathological findings in patients with FOBMD, but here we have a bilateral involvement of the mandible. Makek and Lello found one case that has bilateral mandibular involvement out of 20 FOBMD cases described in their study. Moreover, according to a literature review by bouquet and his colleagues 6 based on 596 cases of FOBMD, 3\% of patients had bilateral occurrence of this lesion within their jaws. In Brazil, two case reports were found regarding bilateral FOBMD in the mandible ${ }^{9,10}$.

Microscopically, to diagnose FOBMD, hematopoietic marrow components such as

erythroid, monocytic, granulocytic and lymphocytic series with megakaryocytes and fatty marrow need to be present. This is an important significance, since the clinical and radiographical findings may be confused with other pathological conditions. As in this report, the well-defined bilateral radiolucency suggest the presence of a benign condition as a cyst or a tumor. In order to differentiate between these conditions, histopathological analysis is 
necessary ${ }^{1,5}$. In contrary, Makek and Lello ${ }^{7}$ believed that a meticulous radiographic evaluation of the lesion may help in reaching a final diagnosis without the need for histopathological analysis. They mentioned three prominent radiographic features to look for; first the lesion is usually round to oval. Second, the lesion usually has a well-defined anterior border that sometimes appears sclerotic, whereas the posterior border is usually poorly defined. Lastly, the lesion can be seen with no internal structures, or trabiculations ${ }^{7}$.

The exact pathogenesis of FOBMD is still unclear. However, three theories are proposed to explain this lesion;1- FOBMD is a remnant of embryonic red marrow that failed to convert to yellow bone marrow ${ }^{5}$, since FOBMD does not appear in adolescence and in adulthood in a similar degree, Barker and coworkers agreed that this theory is unlikely to be true $e^{4}$. 2- hyperplasia of the bone marrow occur to compensate the increase of functional demand for the blood cell in the cases of the systemic disease. However, few reports is supporting this theory specially with systemic condition such as sickle cell anemia6. Sanner and Ramin ${ }^{12}$ reported a case of a 48 -yearold male with sickle cell anemia, who has a bilateral mandibular involvement with FOBMD. 3- Abnormal bone regeneration occurs in an area with previous trauma or surgery $^{5}$ such as tooth extraction ${ }^{7,8}$ or dental implant ${ }^{13,14}$. Shankland and $\mathrm{C}$ suggested that this defective bone regeneration is due to transient ischemic osteoporosis as a result of the interruption blood flow within the bone marrow. Moreover, according to Gurevitch and his colleagues $^{16}$, fatty bone marrow has mesenchymal progenitor cells, which have the ability to produce hematopoietic microenvironment ${ }^{15}$. In 2011, a research study was conducted by Lee and others ${ }^{17}$, in which they were able to isolate these cells from mandibular marrow aspirates. Therefore, the third theory appears to be the most reasonable in this case, since the lesions exists in an edentulous area with history of previous surgical extractions. This theory might also explain the redeveloping of the lesion after implant placing. Overheating of bone or peri-implant bone compression may cause FOBMD around implants as a defective healing response to surgical trauma $^{15}$. However, trauma during the removal of the lesion may also explain the reoccurrence of new one. ${ }^{13}$

\section{CONCLUSION}

In order to diagnosis FOBMD and differentiate it from other lesions, a thorough clinical and radiographic examination with histopathological analysis is necessary. No treatment is required for it. Further researches are needed regards this topic to help us fully understand it, since the exact incident and etiology of FOBMD are not established yet.

\section{ETHICAL DISCLOSURES}

\section{A.Protection of human and animal subjects}

The authors declare that no experiments were performed on humans or animals for this study.

\section{B. Confidentiality of data}

The authors declare that they have followed the protocols of their work center on the publication of patient data.

\section{Right to privacy and informed consent} The authors have obtained the written informed consent of the patients or subjects mentioned in the article. The corresponding author is in possession of this document.

\section{CONFLICTS OF INTEREST}

The authors have no conflicts of interest to declare.

\section{REFERENCES}

[1] Schneider LC, Mesa ML, Fraenkel D. "Osteoporotic bone marrow defect: radiographic features and pathogenic factors". Oral Surg Oral Med Oral Pathol 65:127Y129 1988.

[2] Shafer WG, Hine MK, Levy BM. "A textbook of oral pathology". 4th ed. Philadelphia: WB Saunders, Ch 10,544-5, 1983

[3] Crawford BE, Weathers DR. "Osteoporotic marrow defects of the jaws". J Oral Surg 1970; 28:600-3.

[4] Barker BF, Jensen JL. Howell FV. "Focal osteoporotic bone marrow defects of the jaws". Oral Surg 1974; 38:404-13

[5] Shankland, II, W.E. and Bouquot, J.E. "Focal osteoporotic marrow defect: report of 100 new cases with ultrasonography scans". CRANIO 2004; 22(4), pp.314-319.

[6] Bouquot JE, Rohrer M, McMahon RE, Boc T. "Focal osteoporotic marrow defect (FOMD) - literature review and report of 596 new cases”. Oral Surg Oral Med Oral Pathol Oral Radiol Endod, 94:211. 2002

[7] Makek M, Lello G. "Focal osteoporotic bone marrow defects of the jaws". J Oral Max fac Surg, 44:268-273, 1986

[8] Lipani CS, Natiella JR, Greene WG. "The hematopoietic defect of the jaws: a report of sixteen cases". J Oral Pathol, 11:411. 1982

[9] Bravo-Calderón, D.M., Oliveira, D.T. and dos Santos, W.H.M. "Bilateral osteoporotic bone marrow defects of the mandible: a case report". Head \& face medicine. 8(1), p.22. 2012

[10] Almeida, L.Y., Kato, R.B., Ribeiro, M.C. and León, J.E. "Focal osteoporotic bone marrow defect mimicking a mandibular cystic lesion". Journal of Craniofacial Surgery, 25(4), pp.e324-e326. 2014

[11] Sewell CMD, Almeida OP, Passeri LA. "Defeito osteoporóticomedula óssea". Rev Assoc Paul Cir Dent. 44:321-323. 1990

[12] Sanner JR, Ramin JE. "Osteoporotic, hematopoietic mandibular marrow defect: an osseous manifestation of sickle cell anemia". J Oral Surg. 35:986-988. 1977

[13] Garcia, N.G., Barros, F.B.A., Carvalho, M.M.D. and Oliveira, D.T. "Focal osteoporotic bone marrow defect involving dental implant: a case report". International journal of implant dentistry. 1(1), p.18. 2015

[14] Bayram B, Alaaddinoglu E. "Implant-box mandible: dislocation of an implant into the mandible". J Oral Maxillofac Surg. 69:498-501. 2011

[15] Sençimen M, Delilbasi C, Gülses A, Okçu KM, Gunhan O, Varol A. Focal osteoporotic hematopoietic bone marrow defect formation around a dental implant: a case report. Int J Oral Maxillofac Implants. 2011; 26:e1-4.

[16] Gurevitch O, Slavin S, Resnick I, Khitrin S, Feldman A "Mesenchymal progenitor cells in red and yellow bone marrow". Folia Biol (Praha), 55:27-34. 2009

[17] Lee BK, Choi SJ, Mack D, Oh SH. "Isolation of mesenchymal stem cells from the mandibular marrow aspirates". Oral Surg Oral Med Oral Pathol Oral Radiol Endod. 112(6): e86-93, 2011 


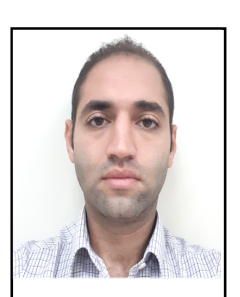

Karim M. Adel*(Corresponding Author)

Born in kuwait Apr 1986 and graduated from Faculty of Dentsitry Ain Shams university, Cairo, Egypt in 2007. Dr Karim was granted his master's degree in oral and maxillofacial surgery from Faculty of Dentistry Ain Shams University, Cairo, Egypt in 2014

$\mathrm{He}$ is former Lecturer assistant in oral and maxillofacial surgery department, Faculty of oral and dental Medicine, Future University in Egypt between 2009 and 2017. $\mathrm{He}$ works as Oral and maxillofacial surgeon unit of Oral and maxillofacial surgery, Bnied-Al-gar Dental Centre and Mubarak-AlKabeer Hospital, Ministry of health, Kuwait since 2015. Among his publications:

*Karim M. Adel et al. Challenges Confront Maxillofacial Surgeons in Management of the Oral Manifestation of Infantile Systemic Hyalinosis: (A Case Report). Int J Dent \& Oral Heal.2018 4:10, 173-175

* KM Ahmed, SA Elfatah, MAEM Katamish, Crestal bone loss of standard implant versus platform switch implant design using minimal invasive technique, Future Dental Journal, 2016;2, 2,74-79,

* A Al-Ramzi, M Kassem, KM Adel Necrotizing fasciitis with toxic shock syndrome in 5-month-old baby: A case report, In Future Dental Journal, 2017; 3,2,80-82 